\title{
CONTRIBUIÇÕES DAS CIÊNCIAS SOCIAIS DIANTE O AVANÇO DO NEOLIBERALISMO
}

“Abya-Yala: revista sobre acesso à justiça e direitos nas Américas” chega ao seu segundo ano de publicação em um cenário político caracterizado por amplas e profundas crises, que apenas reforçam a importância e a atualidade de fomentar $o$ periódico enquanto veículo de produção e difusão de conhecimento no campo das ciências sociais e do pensamento crítico latino-americano.

Testemunhamos o avanço do neoliberalismo e suas consequências, tais como a intensificação das desigualdades sociais, o aumento da concentração de renda, a precarização das relações de trabalho, o aprimoramento do capitalismo com a financeirização dos mais variados aspectos relacionados à manutenção da vida, a evidenciação das forças conservadoras, por meio da vocalização de discursos de ódio, de demonstração de intolerâncias, de diversificação das formas de discriminação e preconceito, a negação do outro, o recrudescimento de políticas repressivas e opressoras, o retorno ao autoritarismo e ao militarismo, o acirramento, enfim, da disputa entre diferentes projetos de sociedade.

Vivemos um contexto em que as democracias e suas retóricas estão sendo desmascaradas pela sua incapacidade concreta de assegurar direitos que foram árdua e duramente conquistados por longos processos de luta e resistência histórica, dos quais participaram, ativamente, atores implicados com a justiça social, dentre os quais, destacam-se, os movimentos sociais.

Diante este cenário, as ciências sociais são provocadas a construir novas possibilidades, a rever conceitos, a formular novas teorias. São provocadas, acima de tudo, a engajar-se com a transformação da realidade na qual estão inseridas. 
Este quarto número de AbyaYala, o primeiro do ano de 2018, confirma seu compromisso com o pensamento crítico latino-americano e apresenta, em seu conteúdo, um rico conjunto de reflexões sobre os processos de resistência nas Américas face o avanço do neoliberalismo.

Confirmando sua estrutura interna, inaugurada quando da publicação de seu primeiro número, Abya-Yala apresenta às leitoras e leitores cinco seções: a primeira delas é dedicada a homenagear pensadoras e pensadores latino-americanos cuja produção seja significativa tanto sob o ponto de vista teórico, como sob o ponto de vista da reflexão crítica e engajada; a segunda seção veicula dossiê temático organizado por pesquisadoras e pesquisadores de referência no campo das ciências sociais nas Américas, e qualificado pelo sistema de dupla avaliação cega; a terceira dá vazão aos trabalhos recebidos pelo fluxo contínuo de submissão de artigos, igualmente submetido a rigorosa dupla avaliação cega; a quarta seção divulga obras de referência através da publicação de resenhas críticas; a quinta e última seção consiste na transcrição de entrevistas realizadas com pensadoras e pensadores latino-americanos.
Nesta edição, a homenagem é feita ao etnólogo Darcy Ribeiro, grande pensador brasileiro que dedicou sua vida a refletir-para-transformar não só o Brasil como, também, a América Latina. Sua trajetória, formação e atuação são apresentados no texto de autoria de Talita Rampin, professora da Universidade Federal de Goiás. Seu percurso teórico é destacado de forma a caracterizá-lo como expressão do pensamento latinoamericano que, como tal, parte das especificidades da região para, então, construir estratégias para superação das situações concretas de desigualdades, violências e opressões.

Essa mesma preocupação e engajamento para superação de situações concretas de violações permeia o dossiê temático organizado por Victoria Chenaut, Annapurna Devi Pandey e Laura R. Valladares. As organizadoras assinam o texto de abertura do dossiê, intitulado "Procesos de resistencia, derechos colectivos y despojo de los bienes comunes en el neoliberalismo", no qual problematizam o papel desempenhado pela academia, pelo ativismo social e jurídico, destacando-os como estratégias que podem contribuir para a construção de alternativas à discriminação, à radicalização e à violência que são 
continuamente praticadas contra aquelas e aqueles que resistem ao avanço do neoliberalismo, nas mais diversas partes do mundo. Nesse sentido, destacam os processos de resistência que tem sido protagonizado por mobilizações Inter setoriais que envolvem movimentos sociais, a sociedade civil organizada, a comunidade acadêmica, dentre outros atores implicados com a defesa de direitos e justiças.

Maria Rocio Bedoya Bedoya, da Universidade de Antioquia, em "Los impactos de las multinacionales mineras, el papel del Estado Colombiano y los procesos de resistencia en Marmato", fornece a estrutura analítica necessária para que possamos compreender a dinâmica do sistema capitalista em sua fase atual, financeira. A partir do estudo dos processos de resistência no Município de Marmato, na Colômbia, a autora configura a estratégia de atuação de empresas multinacionais na América Latina frente a um modelo de desenvolvimento econômico - que é, também, político, social e cultural - que viabiliza o avanço de projetos extrativistas minero-energéticos devastadores sob o ponto de vista ambiental, territorial, social, político e econômico. Fica evidenciada, em sua análise, que a incidência das multinacionais tem reconfigurado as estruturas e relações locais, modificando a atuação do Estado de modo a reorientar sua ação para a viabilização de empreendimentos que tem, como fundo, a exploração dos recursos naturais em regiões periféricas.

E é desde a periferia do sistema mundial, para além da espacialidade geossocial da América Latina, que Binay Kumar Pattnaik e Sanghamitra Patra dão continuidade às reflexões iniciadas por Bedoya Bedoya. Localizando seu olhar desde e para a Índia, os autores de "Intercine between the Indian State and the Adivasis (Indigenous People) under NeoLiberalism: A case of Lanjigarh Resistance Movement", analisam outro processo de resistência, o movimento anti Vedanta em Lanjigarh, no distrito de Kalahandi, no interior do estado indiano de Odisha. O caso retratado envolveu uma situação em que 302 famílias Adivasis foram desabrigadas e seu território devastado pelo avanço das estruturas neoliberais materializadas em projetos de modernização. Nele, problematiza a imposição de um modelo de desenvolvimento e os seus reflexos para a população local, enfatizando as formas de resistência que foram adotadas pelas famílias e a 
complexa relação que é estabelecida entre Estado, sociedade civil e população local.

Faye V. Harrison, por sua vez, em "From Standing Rock to Flint and Beyond:Resisting Neoliberal Assaults on Indigenous, Maroon, and Other Sites of Racially Subjected Community Sustainability in the Americas", analisa outra situação de resistência ocorrida em reação ao avanço neoliberal em busca de recursos, desta vez, hídricos. A partir dos processos de mobilização realizados pela tribo Standing Rock Sioux, na Dakota do Norte, Estados Unidos da América, em coalizão formada com ativistas de outras nações indígenas, incluindo representantes da Bacia Amazônica, de movimentos não indígenas e de organizações políticas como o Partido Verde e o Black Lives Matter, as situações de violações dos direitos humanos experimentadas alcançaram projeção nacional e ganharam destaque no debate político nos EUA, assim como, a reflexão sobre as reivindicações a direitos coletivos que historicamente tem sido empreendidas pelos povos e movimentos afrodescendentes e indígenas, para além dos direitos à terra, ao desenvolvimento e aos recursos culturais.
Apesar das diferenças evidentes que emergem da localização geográfica desses dois casos analisados, persistem elementos em ambos que permitem identificarmos um mesmo padrão se repetindo na forma com a qual o capitalismo modula os padrões de desenvolvimento em nível mundial e, com eles, também os padrões de violações que são sistematicamente perpetradas contra os povos e os ambientes geossociais situados em regiões estratégicas, principalmente quando o são sob o ponto de vista dos recursos naturais.

Essa constatação nos leva a um imperativo que talvez represente um dos maiores desafios colocados para as gerações atuais: identificar esses padrões para que possamos construir alternativas viáveis para superá-los. Outro desafio, como bem aponta Anahy Gajardo em "Between Support and Marginalization: the Process of the Diaguita's Re-emergence in the Age of Neoliberal Multiculturalism (Chile)", é dimensionar os efeitos sociais e identitários do multiculturalismo neoliberal, em um contexto em que se mundializam não só as relações financeiras mas, também, se complexificam as relações jurídicas e de poder, inclusive na dimensão que 
envolve os Estados, as empresas multinacionais e os atores não estatais implicados na realização de ações que, embora possam ser desempenhadas pelos Estados nacionais, acabam sendo relegadas a um plano que passa a ser ocupada por este novo ator. É nesse sentido que o sexto artigo do dossiê, "The Role of Non State Actors in Ensuring Indigenous Right to Education in an Era of Neo liberalism: an Experiential Account from India", de Navaneeta Rath e Annapurna Pandey, é desenvolvido.

Por fim, encerrando o dossiê, "The Privatization of Environmental Discourse: Clean Development and Indigenous Territoriality in Western Panama", de Osvaldo Jordan. Nele, o autor analisa o caso da Hidroelétrica Barro Blanco, no Panamá, problematizando os discursos e usos do desenvolvimento sustentável, provocando-nos a refletir sobre os paradoxos de sua contraposição aos direitos humanos e das populações locais. Afinal, quanto valem os direitos?

A mesma tônica de olhar crítico e apurado sobre a realidade neoliberal e as práticas que são assumidas neste contexto, permeia os artigos recebidos em fluxo contínuo pela revista. Em “Cortes Superiores y Políticas de Acción Afirmativa: Aspectos de las
Decisiones en Brasil y Contribuciones para Investigaciones Futuras", Ana Claudia Farranha enfoca as práticas judiciais, em especial, aquelas que são praticadas por cortes superiores em sede de apreciação jurisdicional de políticas de ações afirmativas. Edgar Belmont Cortés e Eduardo Aristóteles Ramírez, por sua vez, em "Reeducar y Trabajar por Resultados: Polémicas Alrededor de la Profesionalización del Trabajo del Policía en Querétaro, México", privilegiam a análise das mudanças notadas nas polícias desde os processos de modificações na forma pela qual é gerida e administrada a justiça no contexto mexicano.

A edição segue com duas resenhas críticas, sendo a primeira de Meztli Yoalli Rodríguez Aguilera, referente ao curta-metragem "Semillas de Guamúchil", e a segunda referente à obra 'De la "Vieja" a la "Nueva" Justicia Indígena. Transformaciones y Continuidades en las Justicias Indígenas de Michoacán”, publicada por Orlando Aragón Andrade no ano de 2016 e resenhado por Erika Bárcena Arévalo. Através dessas resenhas, a publicação cumpre outro importante papel no campo das ciências sociais: o da difusão de conhecimento já produzido, tornando acessíveis análises 
promovidas por pesquisadoras $\mathrm{e}$

pesquisadores sobre a produção de outros pensadores e pensadoras latinoamericanos. O número é encerrado com uma intrigante entrevista com Mercedes Olivera, realizada por Marisa Ruiz Trejo sobre os aportes da antropologia feminista em Chiapas, México, e as ausências de referências às mulheres no campo da produção do conhecimento.

Engajada, provocativa e crítica: esta é a quarta edição que compartilhamentos com o público leitor.

Desejamos a todas e a todos uma excelente leitura!

Rebecca Lemos Igreja, Maria Teresa Sierra Camacho, Fernando Dantas e Talita Rampin 